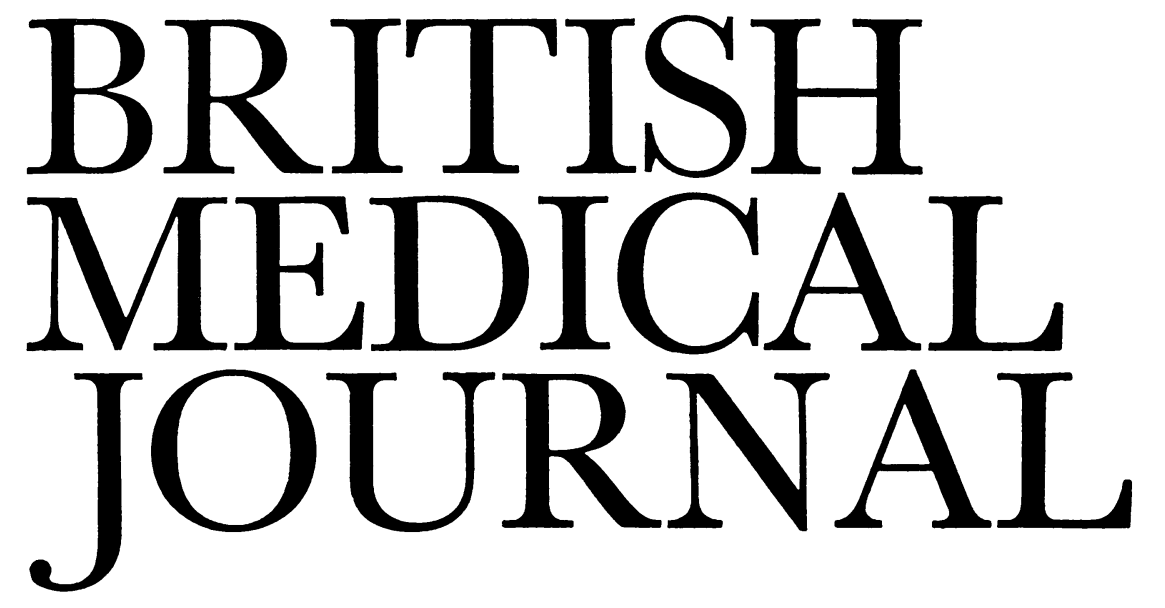

LONDON, SATURDAY 2 AUGUST 1980

\title{
Sudden infant death syndrome and ventilatory control
}

Sudden infant death syndrome remains a tragic, poorly understood condition killing at least one in every 1000 apparently healthy babies in the first year of life. Epidemiological studies ${ }^{1}$ have shown that adverse social factors play a large part in the selection of victims, and careful necropsies ${ }^{2}$ have indicated that no single set of circumstances is likely to be found responsible for these deaths. None the less, evidence is accumulating that abnormalities of the ventilatory control mechanisms may be an important prerequisite.

Death is often preceded by coryzal symptoms, and over $40^{\circ}$, of infants dying unexpectedly have mucosal changes indicating the presence of viral upper respiratory tract infection. ${ }^{3}$ Recent studies ${ }^{4}$ have shown that babies with even mild upper airway infections tend to develop periodic respiration with attacks of apnoea (a pattern frequently seen in preterm babies), suggesting that viraemia may upset the respiratory control mechanism. Some of these babies found apnoeic have been resuscitated with difficulty by their parents and labelled "near-miss" sudden infant death syndrome on the reasonable assumption that if not discovered they would have died. Certainly these babies often have grossly abnormal respiratory patterns in the next few days, and have a risk of subsequent sudden death of about $10 \%$, which is $50-100$ times greater than average. These findings have led many investigators to the conclusion that prolonged apnoea is likely to be the final event in at least some sudden infant deaths.

Even in health the ventilatory response to arterial carbon dioxide varies widely from person to person, and members of the same family tend to have a similar pattern of response. ${ }^{5}$ One line of research into the sudden infant death syndrome has explored the hypothesis that some (if not all) of these babies come from the fraction of the population with least chemoreceptor drive. Shannon and his colleagues ${ }^{6}$ found that infants who had had near misses of the sudden infant death syndrome had less ventilatory response to inhaled carbon dioxide than controls and had higher resting alveolar tensions of carbon dioxide. The ventilatory response to hypoxia may also be impaired in these babies. ${ }^{7}$ Other workers have found that siblings of victims of the sudden death syndrome have more periodic respiration than matched controls ${ }^{8}$ and sometimes have poor carotid body function, as measured by the ventilatory response to a single inspiration of carbon dioxide. ${ }^{9}$

Studies from the Rutgers Medical School, New Jersey, ${ }^{10}$ have shown that the parents of infants who died suddenly also have atypical ventilatory control, tending to have a reduced ventilatory response to carbon dioxide as measured both by changes in the minute volume and also by the intrathoracic pressure generated during the first 100 milliseconds of inspiration against a total obstruction (P100). This second procedure provides a direct measurement of the output of the respiratory centre before appreciable air flow has started and so is independent of the mechanical characteristics of the lung. One finding of great interest was that the normal compensatory increase in P100 when respiration is loaded by including air resistance in the inspiratory line was absent in virtually all the parents of victims of the sudden infant death syndrome.

These findings make it very likely that children with impaired chemoreceptor ventilatory drive have a greater than normal chance of succumbing to the sudden infant death syndrome. Possibly a high-risk group could be identified by monitoring ventilation, perhaps combined with some simple measure of carbon dioxide responsiveness in the immediate neonatal period. If this proves practicable then the widespread use of apnoea monitors in the home will have to be considered. Meanwhile the best hope in the short term comes from identification of high-risk groups on the basis of the obstetric and neonatal history and social factors.

${ }^{1}$ Carpenter RG, Gardner A, McWeeny PM, Emery JL. Multistage scoring system for identifying infants at risk of unexpected death. Arch Dis Child 1977;52:606-12.

${ }^{2}$ Sinclair-Smith C, Dinsdale F, Emery J. Evidence of duration and type of illness in children found unexpectedly dead. Arch Dis Child 1976;51: 424-9.

${ }^{3}$ Steinschneider A. Nasopharyngitis and the sudden infant death syndrome. Pediatrics 1977;60:531-3.

${ }^{4}$ Bruhn FW, Mokrohisky ST, McIntosh K. Apnea associated with respiratory syncytial virus infection in young infants. $\mathcal{F}$ Pediatr 1977;90:382-6.

${ }^{5}$ Arkinstall WW, Nirmel K, Klissouras V, Milic-Emili J. Genetic differences in the ventilatory response to inhaled $\mathrm{CO}_{2}$. F Appl Physiol 1974; $36: 6-11$.

${ }^{6}$ Shannon DC, Kelly DH, O'Connell K. Abnormal regulation of ventilation in infants at risk for sudden-infant-death syndrome. $N$ Engl $\mathcal{f} \mathrm{Med}$ $1977 ; 297: 747-50$.

7 Hunt CE, McCulloch K, Brouillette RT. Decreased hypoxic ventilatory response in near-miss sudden infant death syndrome. Pediatr Res 1980; 14:644.

${ }^{8}$ Kelly DH, Walker AM, Cahen LA, Shannon DC. Periodic breathing in siblings of SIDS victims. Pediatr Res 1980;14:645.

9 Gurwitz D, Spriet LL, Bryan MH, Bryan AC. Carotid body function in siblings of SIDS. Pediatr Res 1980;14:643.

10 Schiffman PL, Westlake RE, Santiago TV, Edelman NH. Ventilatory control in parents of victims of sudden-infant-death syndrome. $N \mathrm{Engl}$ f Med $1980 ; \mathbf{3 0 2}: 486-91$. 